\title{
Outcome, quality of life and direct costs after out-of-hospital cardiac arrest in an urban region of Switzerland
}

\author{
Raphael Ruch®D, Laura Stoessel, Philipp Stein, Michael Thomas Ganter ${ }^{*}$ and Daniel Anthony Button
}

\begin{abstract}
Background: Considering the significant morbidity and mortality of out-of-hospital cardiac arrest, only little data on survival or quality of life after successful resuscitation is available in Europe. Additionally, economic aspects of such events are poorly studied. The purpose of this study is to provide data for survival, quality of life and costs directly related to the cardiac arrest for a region of Switzerland served by one emergency medical service (EMS).

Methods: Eighty eight patients older than 18 years of age that were resuscitated by the EMS Winterthur in the year 2013 were included and retrospective analysis of EMS-protocols was performed. For patients alive at follow-up, 2 years after the event, a structured interview with quality of life questionnaires was conducted. This study was accepted by the local Ethics Committee.

Results: Thirty five percent $(n=31)$ of resuscitated patients were admitted alive to the hospital following out-of-hospital cardiac arrest. This incidence was as high as $60 \%$, if the patients had a shockable rhythm as first rhythm. Survival to followup was 16\% $(n=14)$. These patients had an excellent quality of life overall, with little to no limitations in daily life. There was no significant difference in survival for patients in outlying regions with comparatively longer timespans until arrival of EMS. Median EMS-costs for deceased patients were CHF 1731 (inter-quartile range 346), for survivors CHF 2'169 (interquartile range CHF 444) and median hospital-costs were CHF 27'707 (inter-quartile range CHF 62'783).
\end{abstract}

Conclusion: Quality of care for patients with out-of-hospital cardiac arrest in the region of Winterthur is high, including patients in outlying regions. The associated costs are similar to other European countries.

Trial registration: This trial was registered with www.clinicaltrials.gov under NCT02625883.

Keywords: Out-of-hospital cardiac arrest, Resuscitation, Quality of life, Hospital cost

\section{Background}

Even though unexpected out-of-hospital cardiac arrest (OHCA) is a disastrous event with significant morbidity and mortality, data on survival after OHCA in Switzerland and even Europe is sparse [1, 2]. In terms of creating evidence by performing prospective randomized studies, only one such trial was published per year in German-speaking Europe between 1990 and 2012 on average [3]. In Switzerland, some data on outcome after OHCA have been published, however, routine reporting is not available although this could serve as an important

\footnotetext{
* Correspondence: michael.ganter@ksw.ch

Institute of Anesthesiology - Emergency Medical Service, Perioperative

Medicine, Pain Therapy, Kantonsspital Winterthur, Brauerstrasse 15, CH-8401

Winterthur, Switzerland
}

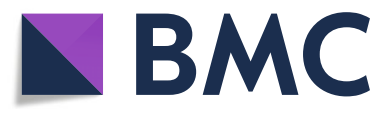

(๑) The Author(s). 2019 Open Access This article is distributed under the terms of the Creative Commons Attribution 4.0 International License (http://creativecommons.org/licenses/by/4.0/), which permits unrestricted use, distribution, and

reproduction in any medium, provided you give appropriate credit to the original author(s) and the source, provide a link to the Creative Commons license, and indicate if changes were made. The Creative Commons Public Domain Dedication waiver (http://creativecommons.org/publicdomain/zero/1.0/) applies to the data made available in this article, unless otherwise stated.

quality marker for prehospital clinical care [4-6]. Studies on quality of life (QoL) are seldom and usually focus on neurological deficit instead of structured and validated QoL-scores [7]. In Switzerland, no analysis of QoL after OHCA exists so far. Additionally, little data is available concerning costs associated with treatment of patients with OHCA. Since resources are limited in our modern health care systems, economic aspects including costs gather more and more attention [8].

The first aim of the present study was to retrospectively analyze the survival after OHCA in the emergency medical service (EMS) Winterthur ("Rettungsdienst Winterthur") in 2013. The second aim was to assess QoL 2 years after OHCA. Finally, the third aim was to 
calculate health care costs from OHCA until hospital discharge of this patient population.

\section{Methods}

This study was approved by the local Ethics Committee of Zurich, Switzerland (KEK ZH 2015-0396) and registered at clinicaltrials.gov (NCT02625883). The need for informed consent of family members of deceased patients was waived, informed consent of surviving patients was obtained.

Our study was a combination of a retrospective analysis, based on EMS Winterthur data from the year 2013, and a structured follow up interview 2 years later with all surviving patients from that data set. All adult patients suffering from OHCA requiring resuscitation by the EMS Winterthur were included. Exclusion criteria were age $<18$ years old and cardiac arrest other than cardiac origin (e.g. trauma, submersion, drug overdose, asphyxia, exsanguination). In addition, patients who denied the use of their data for research purposes and patients with incomplete datasets were not included in data analysis.

Data for OHCA was collected according to Utstein criteria $[9,10]$. Location and address of the cardiac arrest was documented. Initial cardiac rhythm was recorded and classified as shockable and non-shockable. Per Utstein criteria, return of spontaneous circulation (ROSC) and/or termination of prehospital cardiopulmonary resuscitation (CPR) were encoded to the database. ROSC was defined as at least a brief $(>30 \mathrm{~s})$ restoration of a spontaneous perfusing rhythm, that provides evidence of more than an occasional gasp, fleeting palpated pulse or arterial waveform according to the Utstein criteria $[9,10]$. Only patients with sustained ROSC were transported to the hospital, otherwise CPR was terminated in the field.

Our primary endpoint was the incidence of sustained ROSC and 2-year survival after OHCA. Second endpoint was QoL at least 2 years after the event. Third endpoint was costs generated by the health care system until first discharge in the care for patients with ROSC after resuscitation for OHCA.

All EMS in the canton Zurich are dispatched by a central emergency call center located at the Zurich airport. In cases of reported cardiac arrest, the dispatcher instructs callers to perform CPR. Although this so-called telephone-CPR has been institutionalized for many years, structured documentation of telephone-CPR has just started recently and was not established at the time of the study. The EMS Winterthur serves the northern part of the canton Zurich (around 250'000 inhabitants) including the city of Winterthur. It consists of 55 fulltime employees, 7 ambulance vehicles and 2 emergency physician transport vehicles and is dispatched to about 25 emergency calls daily, around 9'100 per year. The resuscitation is performed according to current advanced life support (ALS) guidelines by the European Resuscitation Council. An emergency physician can be mobilized by paramedics already on site or may accompany the ambulance crew from the beginning, depending on the severity of the reported emergency. Additionally, there exists a countrywide physician-staffed, helicopterbased EMS for calls to more remote or mountainous regions. None of our analysed cases was handled by these crews, however.

\section{Survival and quality of life}

Data sources included Utstein and operational protocols including timestamps from EMS Winterthur and - for surviving patients - medical records from hospitals and rehabilitation clinics.

Data on QoL was collected using the subjective classification with the Cerebral Performance Category (CPC) [11], the EQ-5D-5 L-questionnaire (EuroQol, The Netherlands) [12] and a 36-item health survey (RAND Health Care, RAND Corporation, Santa Monica, CA).

Although not validated, the easy to use CPC-scale is widely being used to assess neurological impairment and provide reliable information on functional outcome categories [13]. CPC-scores range from 1 to 5, scores 1 to 3 indicating no, mild or severe cerebral damage, 4 representing coma or a vegetative state and 5 brain death.

The EQ-5D-5 L-questionnaire is a validated QoL-score analyzing 5 dimensions of health, mobility, self-care, usual activities, pain/discomfort, anxiety/depression in 5 levels from 1 to 5 , representing no problems, slight, moderate, severe problems or inability to perform, respectively. Additionally, it includes a visual analog scale for general health ranging from 0 to 100 . It is available in a German translation, so it can be safely used in our German speaking population. Although standard values for Switzerland do not exist, the score has been used to determine standard values for many European countries, most of them with a health care standard comparable to Switzerland $[14,15]$. These population norms were collected for the 3-level version of the questionnaire, they can however be used for the 5-level-version as well [16].

The RAND 36-item health survey was added as an additional, more extensive, tool to assess QoL. Its 36 questions are merged into a percentile rank in eight different health-related dimensions, physical functioning, role limitations due to physical health, role limitations due to emotional problems, energy/fatigue, emotional well-being, social functioning, pain and general health.

\section{Financial aspects}

For patients with ROSC, we considered the invoicetotals (direct costs) from EMS and hospitals until first discharged. 


\section{Statistical analysis}

Statistical analysis was performed with $\mathrm{R}$ version 3.5.0, published under the GNU general public license (The $\mathrm{R}$ foundation for statistical computing, www.r-project.org, Vienna, Austria, 2018). Methods used were linear regression with least squares for continuous data, Student's ttest for group-comparison and Fisher's exact test for nominal data. Data is shown as median and interquartile range (IQR) and mean \pm standard deviation (SD) if not displayed differently. The significance threshold was set at .05 .

\section{Results}

A total of 91 patients were resuscitated by the EMS Winterthur due to cardiac arrest in 2013. Of them, three individuals were excluded due to missing initial cardiac rhythm. Demographic data and baseline characteristics of the 88 patients studied is shown in Table 1 and as an Utstein style flowchart in Fig. 1.

\section{Survival}

Follow-up examination was done at the end of the year 2015, in median 2 years and 7.5 months after the OHCA event (IQR 6.5 months).

Table 1 Descriptive statistics of our collective

\begin{tabular}{ll}
\hline Total number of patients, $\mathrm{n}$ & 88 \\
Female, $\mathrm{n}(\%)$ & $27(31)$ \\
Mean age, years & $68 \pm 17$ \\
Initial rhythm & \\
Ventricular fibrillation, $\mathrm{n}(\%)$ & $30(34)$ \\
Ventricular tachycardia, $\mathrm{n}(\%)$ & $0(0)$ \\
Pulseless electrical activity, $\mathrm{n}(\%)$ & $28(32)$ \\
Asystole, $\mathrm{n}(\%)$ & $30(34)$ \\
ROSC, $\mathrm{n}(\%)$ & $31(35)$ \\
Collapse witnessed, $\mathrm{n}(\%)$ & $59(67)$ \\
Bystander resuscitation, $\mathrm{n}(\%)$ & $50(57)$ \\
Distance to hospital, km & $7 \pm 6$ \\
Time parameters & \\
Time from EMS activation to arrival on scene, min & $9 \pm 4$ \\
Time from arrival to defibrillation, min & $7 \pm 6$ \\
Time from arrival to ROSC, min & $19 \pm 11$ \\
Time from arrival to discontinuation of resuscitation \\
efforts, min \\
Therapy & $20 \pm 14$ \\
Defibrillation, $\mathrm{n}$ (\%) & \\
Epinephrine administered, \% n (\%) & \\
Amiodarone administered, $\mathrm{n}(\%)$ & $35(40)$ \\
\hline
\end{tabular}

Results are presented as $n$ (percentage of population) or mean \pm standard deviation respectively; EMS emergency medical service, ROSC return of spontaneous circulation
Of the overall 88 patients included in data analysis, $35 \%(n=31)$ had sustained ROSC and survived to hospital admission, $18 \%(n=16)$ were alive at hospital discharge and $16 \%(n=14)$ were still alive at follow-up. Thirty of those 88 patients had a shockable initial rhythm (ventricular fibrillation, VF). The outcomes of this subgroup were as follows: $60 \%(n=18)$ had sustained ROSC and survived to hospital admission, 47\% $(n=14)$ were alive at hospital discharge and $43 \%(n=13)$ were still alive at follow-up.

Patients with ROSC mostly had VF and pulseless electrical activity (PEA) as initial rhythm (VF: 58\%, PEA $39 \%$, asystole $3 \%$ ), while asystole was predominant in patients without ROSC (VF: 21\%, PEA 28\%, asystole: $51 \%$ ). The higher rate of ROSC was significant for VF and PEA compared to asystole ( $p<.005$ for both), however there was no significant difference between VF and PEA $(p=.29)$. Additionally, ROSC could be established more often, if the collapse was witnessed $(90 \%$ vs $54 \%$, $\mathrm{p}<.005)$. The percentage of bystander resuscitation was similar in both groups with $52 \%$ in the ROSC-group and $60 \%$ in the non-ROSC-group $(p=.5)$.

Between the ROSC and non-ROSC-group there was no significant difference in the mean distance to the hospital $(6 \pm 4 \mathrm{~km}$ vs $8 \pm 4 \mathrm{~km}, p=.2)$ and mean time from alarm to arrival of EMS on scene $(8 \pm 6 \mathrm{~min}$ vs $9 \pm 6 \mathrm{~min}$, $p=.1$ ). Figure 2 shows the distribution of cases over the area of operations of EMS Winterthur.

The ROSC-group (compared to non-ROSC-group) had a higher incidence of a shockable rhythm (61\% vs $28 \%, p<.005)$. There was no significant difference in the mean dose of epinephrine administered between patients with ROSC or no ROSC (1.9 mg vs $1.8 \mathrm{mg}, p=.9$ ), nor depending on initial rhythm (VF: $2.2 \mathrm{mg}$, PEA: $1.7 \mathrm{mg}$, asystole: $1.5 \mathrm{mg}$; VF vs PEA: $p=.4$; VF vs asystole: $p=.3$; PEA vs asystole: $p=.7$ ).

\section{Quality of life}

Of the 14 patients alive at follow-up, one was in critical condition and died before filling in the questionnaire and another did not consent. Thus, we conducted interviews with 12 patients.

Neurological outcome in all surviving patients was good, 11 patients were assigned a CPC-score of 1 (no cerebral damage). Only one patient had a CPC-score of 2 (mild cerebral damage). The results of the EQ-5D-5 L questionnaire and the RAND 36-item health survey are given in Table 2.

Of the 12 patients that could be interviewed at followup, only 1 had a PEA as initial rhythm. The initial rhythm of all other patients who were still alive and able to conduct the interview was VF. The only patient with a CPC-score of 2 was in the group of VF. 


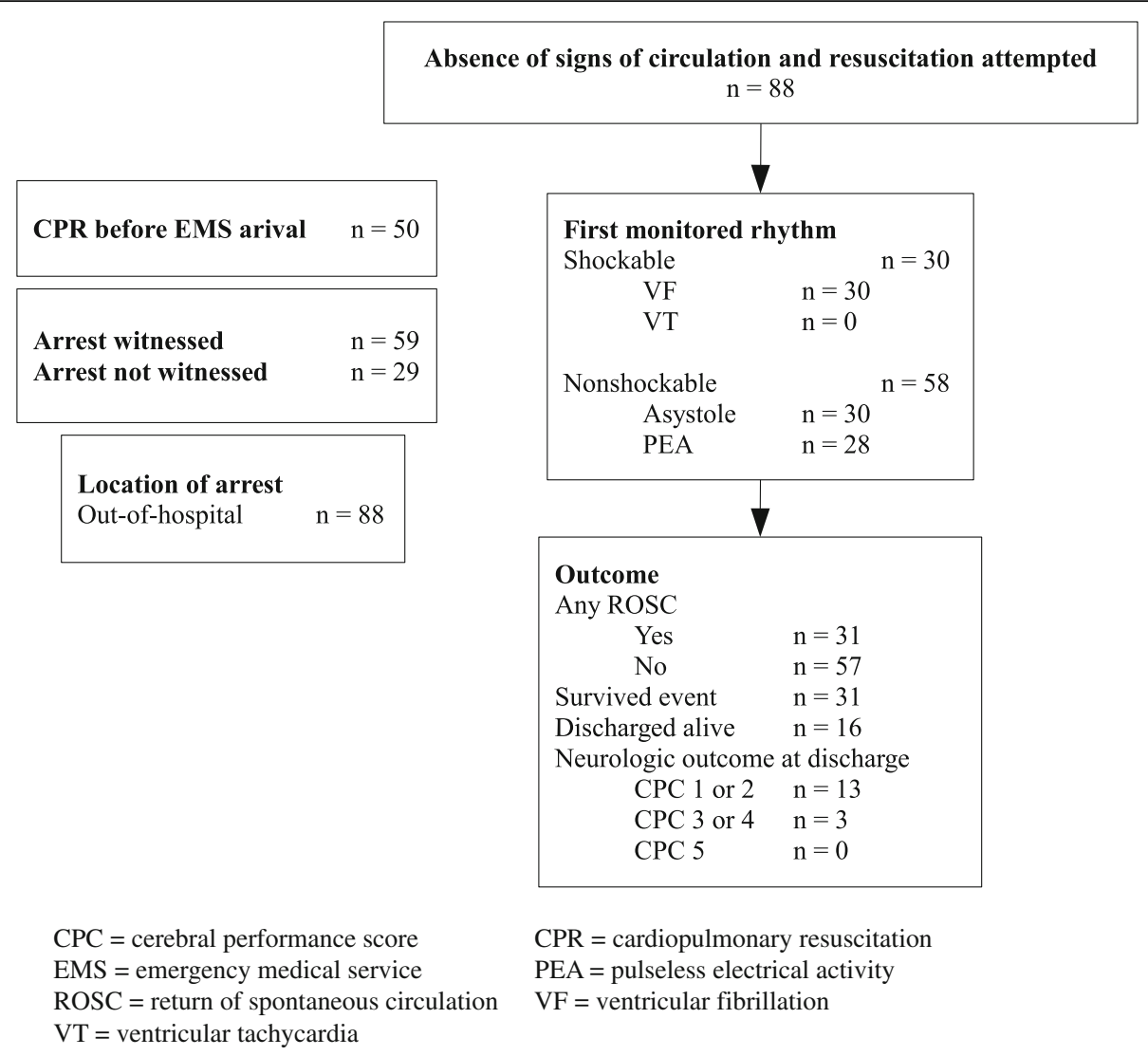

Fig. 1 Utstein style flowchart of our patient collective

Table 3 presents the data for QoL in a different manner to enable comparison of our results, using population norms for EQ-5D, which are available for the 3level version of the questionnaire $[14,16]$. Since wholepopulation responses usually include very few people reporting any problems at all, the results are essentially reported in percentage of people with a score higher than one, thus converting the 3- or 5-level dimensions into 2-level dimensions (problems vs no problems). Of the available population norms, Netherlands' and Belgium's health system seem most comparable to Switzerland [15] and are thus added in Table 3.

\section{Financial aspects}

Length of stay in hospital, EMS costs and hospital costs are given in Table 4. If patients had ROSC, EMS costs were significantly higher than for patients without ROSC $(p<0.005)$. Hospital costs increased significantly with length of stay in the hospital $(p<.005)$. There was however no significant difference with regard to survival to discharge from hospital for either $(p=.14)$. Also, there was no significant difference in costs depending on whether or not the initial rhythm was shockable $(p=.46)$.

\section{Discussion}

Our ROSC-rate of $35 \%$ is higher than the $25 \%$ the EuReCa ONE-study found for an European average [2]. However, ROSC-rate was equal to the $32 \%$ found in a recent study in our neighboring city of Zurich, Switzerland after widely training all Zurich police forces to provide basic life support and equipping all police cars with automated external defibrillators [4]. Additionally, all surviving patients reported good neurological outcomes as well as overall good QoL compared with population norms, as found in multiple other QoLstudies $[7,17,18]$.

\section{Survival}

Looking at the rate of survival to discharge, our $18 \%$ compare to the 13.2\% found in an Australian study [18]. A study concerning the Swiss canton of Ticino found survival rates of $56 \%$ to hospital and $24 \%$ at 1 year, they however only considered patients presenting with shockable initial rhythms [5], for this subgroup, our percentage rises to $60 \%$ survival to hospital and $43 \%$ alive at follow-up. A higher survival rate for patients with VF was also found in the EuReCa ONE-study [2]. 


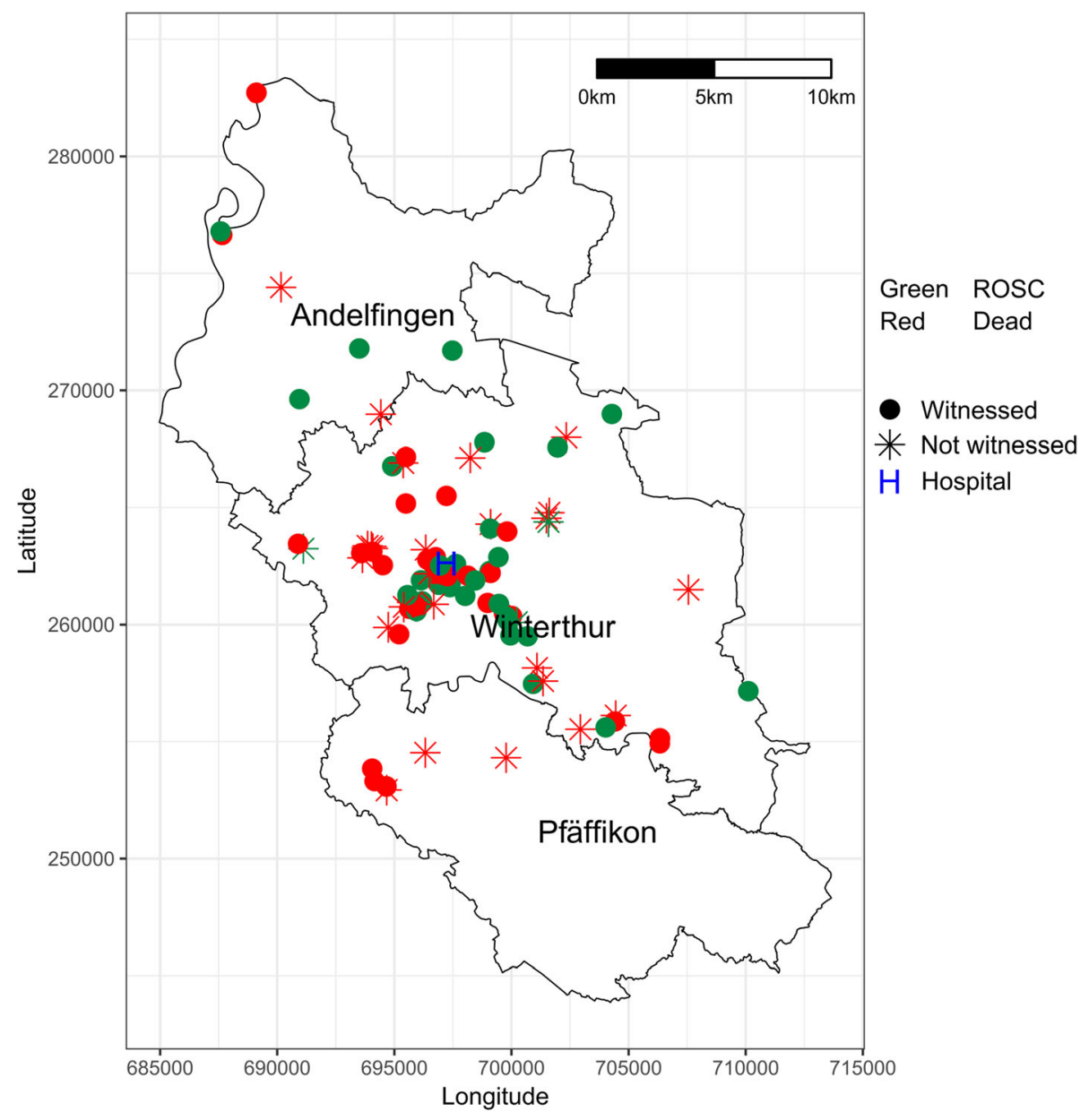

Longitude and latitude are given in the Swiss coordinate system

(Swiss grid); ROSC = return of spontaneous circulation

Fig. 2 Distribution of out-of-hospital resuscitation by the emergency medical service Winterthur in 2013

These results seem to indicate a high quality of care. A contributing factor for a higher percentage of survival might be the predominantly urban area of operations of EMS Winterthur effecting relatively short timespans from alarm to EMS-arrival on scene.

Bystander resuscitation was 52\%, slightly lower than the $57 \%$ found by Mauri et al. [5] but higher than the $42 \%$ found by Sauter et al. [6] and the $47 \%$ average in Europe [2].

Distance to hospital not being a factor in survival or ROSC is somewhat surprising, however the similarity in time from alarm to arrival of EMS on scene for ROSCvs. non-ROSC-group suggests that there existed no significant time difference either to resuscitation or - if bystander resuscitation was performed - to transfer of resuscitation-efforts to EMS.

In our study, although the study sample was small, the administration of epinephrine neither had a positive effect on the survival-rate, nor did it impair neurological outcomes contrary to a recent randomized trial [19].

\section{Quality of life}

It has been claimed that full neurological recovery in patients with out-of-hospital cardiac arrest and shockable initial cardiac rhythm should at least reach 30\% [20]. This number can serve as quality indicator for EMS, which has been well achieved by the EMS Winterthur.

Our good neurological outcome - all patients reporting CPC-scores of 1 or 2 - is also reflected in the EQ-5D-5 L scores, where no patients reported any problems with self-care. Table 3 shows a higher incidence of problems in the mobility- and anxiety/depression-dimensions for our collective compared with population standard values from Belgium and the Netherlands. This is probably attributable to the higher age of our 
Table 2 Results of the EQ-5D-5 L questionnaire and RAND 36item health survey

\begin{tabular}{ll}
\hline Category & Score \\
\hline EQ-5D-5 L & $1.5(1 / 3)$ \\
Mobility & $1(1 / 1)$ \\
Self-Care & $1(1 / 2)$ \\
Usual activities & $1(1 / 3)$ \\
Pain/discomfort & $1(1 / 3)$ \\
Anxiety/depression & $87.5(50 / 100)$ \\
VAS & \\
RAND 36 & $95(55 / 100)$ \\
Physical functioning & $100(0 / 100)$ \\
Role limitations (due to physical health) & $100(0 / 100)$ \\
Role limitations (due to emotional problems) & $70(25 / 85)$ \\
Energy/fatigue & $80(32$ / 96) \\
Emotional well-being & $100(62.5 / 100)$ \\
Social functioning & $100(32.5 / 100)$ \\
Pain & $77.5(40 / 90)$ \\
General Health &
\end{tabular}

Results are shown as median (min/max). EQ-5D-5 L (except for VAS): scorerange $1-5,1=$ no problems, $5=$ extreme problems, VAS $=$ visual analog scale for general health, 0-100. RAND 36: percentile score, a lower score means more limitations/problems

patient collective. The other values are well within expected population standard values [14].

The RAND 36-item health survey showed pronounced role limitations due to physical health for one patient and due to emotional problems for 2 patients. This is not reflected in CPC or EQ-5D-5 L and might be an overestimation due to the limited differentiation in the RAND-questionnaire, offering only 3 levels of discrimination for the respective questions.

\section{Financial aspects}

Analysis of costs with regards to neurological outcome was not possible, with only one patient having a differing CPC-score.

Table 3 Population standard values for the EQ-5D-5 L questionnaire for Belgium and the Netherlands [14] compared to our results from the emergency medical service (EMS) Winterthur

\begin{tabular}{llll}
\hline Category & EMS Winterthur & Belgium & Netherlands \\
\hline Mobility, \% & 50 & 12.6 & 11.5 \\
Self-Care, \% & 0 & 4.0 & 3.4 \\
Usual activities, \% & 17 & 12.4 & 13.5 \\
Pain/discomfort, \% & 17 & 28.5 & 34.2 \\
Anxiety/depression, \% & 33 & 6.6 & 3.5 \\
VAS & 87.5 & 71.3 & 78.0 \\
\hline
\end{tabular}

Other than VAS, numbers show percentage of people reporting problems (by marking a score higher than 1); VAS norms are given for the age group of 65 - 74y, VAS = visual analog scale for general health, 0-100
Table 4 Costs for emergency medical service and hospital and length of stay in hospital (LOS)

\begin{tabular}{ll}
\hline All patients without ROSC & \\
EMS costs, CHF & $1731(795 / 2458)$ \\
All patients with ROSC & \\
LOS, days & $10(1 / 58)$ \\
EMS costs, CHF & $2^{\prime} 168\left(1^{\prime 2} 262 / 2^{\prime} 704\right)$ \\
Hospital costs, CHF & $28^{\prime} 079\left(2^{\prime} 296 / 330^{\prime} 337\right)$ \\
Patients with ROSC surviving to discharge & \\
LOS, days & $19(5 / 58)$ \\
EMS costs, CHF & $2^{\prime \prime} 101\left(1^{\prime} 700 / 2^{\prime} 704\right)$ \\
Hospital costs, CHF & $32^{\prime} 909\left(3^{\prime} 802 / 330^{\prime} 337\right)$ \\
Patients with ROSC not surviving to discharge & \\
LOS, days & $5(1 / 47)$ \\
EMS costs, CHF & $2^{\prime 2} 212\left(1^{\prime} 262 / 2^{\prime} 636\right)$ \\
Hospital costs, CHF & $27^{\prime} 335\left(2^{\prime 2} 296 / 104^{\prime} 435\right)$ \\
\hline Results are shown as median (min/max) &
\end{tabular}

EMS-costs for resuscitated patients was negligible compared to hospital-costs. As most post-resuscitationpatients spend at least some time in an intensive care unit with costly infrastructure and expensive personnel, this comes as no surprise. These investments also explain why length of stay in hospital is the main-factor determining hospital-costs.

As financial data for Switzerland is missing, we need to compare our median costs of CHF 28'079 with other countries. Studies in Japan and the Netherlands found similar values [21, 22], while Finland, the UK and Germany reported higher numbers [17, 23, 24].

According to a study comparing hospital-costs for treating ST-elevation myocardial infarction with care after OHCA, the financial parameters for these two entities were similar [25].

\section{Limitations}

This study has several limitations. First, the number of patients is relatively small. However, this data shows that our prehospital care system including first responders has a high standard of care and is at least comparable to other published European centers. Second, our results describe the survival rate and QoL of a specific population served by one EMS only and therefore may not automatically be applicable to other EMS systems.

In 2 instances the ambulance dispatched to the OHCAcase was not departing from the EMS-headquarters but rerouted on return from another assignment. This may influence the registered distance from the hospital to the site of the OHCA-event. 


\section{Conclusion}

This is one of the first Swiss studies to collectively investigate outcome, quality of life and financial aspects in out-of-hospital resuscitation. Quality of care for patients with out-of-hospital cardiac arrest in Winterthur seems to conform to European standards. Survival being independent of distance to hospital suggests a high standard of care by first responders covering outlying regions. While QoL for patients with OHCA seems to be very good, further research, especially using larger case numbers, could focus on QoL after OHCA, identifying specific problem areas in QoL. Potential therapeutic measures could then be evaluated to improve on these main causes of lost QoL. In addition, more research into financial aspects of OHCA is needed, focusing on direct costs (hospital, EMS and rehabilitation) as well as indirect costs (absence at work due to illness, loss of productive life-years).

\begin{abstract}
Abbreviations
ALS: advanced life support; CPC: cerebral performance score; CPR: cardiopulmonary resuscitation; EMS: emergency medical service; IQR: inter-quartile range; LOS: length of stay; OHCA: out-of-hospital cardiac arrest; PEA: pulseless electrical activity; QoL: quality of life; ROSC: return of spontaneous circulation; SD: standard deviation; VAS: visual analog scale; VF: ventricular fibrillation
\end{abstract}

\section{Acknowledgments}

We would like to thank Dr. U. Held and K. Reeves from the Epidemiology, Biostatistics and Prevention Institute of the University of Zurich for descriptive statistical analysis and creation of Fig. 2. In addition, we thank Dr. Jan Hiss for proof reading.

\section{Authors' contributions}

RR handled ethics application, conducted part of the interviews, evaluated the questionnaire-results, merged data from questionnaires and EMS, conducted statistical analysis and wrote and revised the manuscript. LS researched adequate QoL-scores, created the questionnaire and conducted most of the interviews. PS revised the manuscript. MG revised the manuscript and advised RR during ehtics application and the publication process. DB initiated the study, created the data set from EMS-data, revised the manuscript and supported RR during the whole process, specifically during ethics application and preliminary statistical analysis. All authors read and approved the final manuscript.

\section{Funding}

The study was done by institutional funding

\section{Availability of data and materials}

The dataset analysed during the current study is available from the corresponding author on reasonable request.

\section{Ethics approval and consent to participate}

This study was approved by the local Ethics Committee of Zurich, Switzerland (KEK ZH 2015-0396). The need for informed consent of family members of deceased patients was waived, informed consent of surviving patients was obtained.

\section{Consent for publication}

Not applicable.

\section{Competing interests}

There are no financial conflicts of interest. DAB is the medical director of the EMS Winterthur.
Received: 8 July 2019 Accepted: 11 November 2019

Published online: 27 November 2019

\section{References}

1. Berdowski J, Berg RA, Tijssen JG, Koster RW. Global incidences of out-ofhospital cardiac arrest and survival rates: systematic review of 67 prospective studies. Resuscitation. 2010;81(11):1479-87.

2. Gräsner JT, Lefering R, Koster RW, Masterson S, Bötiger BW, Herlitz J, Wnent J, Tjelmeland IB, Ortiz FR, Maurer H, et al. EuReCa ONE-27 nations, ONE Europe, ONE registry: a prospective one month analysis of out-of-hospital cardiac arrest outcomes in 27 countries in Europe. Resuscitation. 2016;105: 188-95.

3. Ausserer J, Abt T, Stadlbauer KH, Paal P, Kreutziger J, Lindner KH, Wenzel V. Out-of-hospital emergency medicine in Germany, Austria and Switzerland randomized prospective studies from 1990 to 2012. Anaesthesist. 2014;63(1): 54-61.

4. Stein P, Spahn GH, Mueller S, Zollinger A, Baulig W, Brueesch M, Seifert B, Spahn DR. Impact of city police layperson education and equipment with automatic external defibrillators on patient outcome after out of hospital cardiac arrest. Resuscitation. 2017;118:27-34

5. Mauri R, Burkart R, Benvenuti C, Caputo ML, Moccetti T, Del Bufalo A, Gallino A, Casso C, Anselmi L, Cassina T, et al. Better management of out-of-hospital cardiac arrest increases survival rate and improves neurological outcome in the Swiss Canton Ticino. Europace. 2016;18(3): 398-404.

6. Sauter TC, Iten N, Schwab PR, Hautz WE, Ricklin ME, Exadaktylos AK. Out-of-hospital cardiac arrests in Switzerland: predictors for emergency department mortality in patients with ROSC or on-going CPR on admission to the emergency department. PLoS One. 2017;12(11): e0188180.

7. Beesems SG, Wittebrood KM, de Haan RJ, Koster RW. Cognitive function and quality of life after successful resuscitation from cardiac arrest. Resuscitation. 2014;85(9):1269-74.

8. Stanger $D E$, Fordyce $C B$. The cost of care for cardiac arrest. Resuscitation. 2018;131:A7-8.

9. Cummins RO, Chamberlain DA, Abramson NS, Allen M, Baskett PJ, Becker L, et al. Recommended guidelines for uniform reporting of data from out-ofhospital cardiac arrest: the Utstein style. A statement for health professionals from a task force of the American Heart Association, the European resuscitation council, the Heart and Stroke Foundation of Canada, and the Australian resuscitation council. Circulation. 1991;84(2):960-75.

10. Jacobs I, Nadkarni V, Bahr J, Berg RA, Billi JE, Bossaert L, et al. Cardiac arrest and cardiopulmonary resuscitation outcome reports: update and simplification of the Utstein templates for resuscitation registries: a statement for healthcare professionals from a task force of the International Liaison Committee on Resuscitation (American Heart Association, European Resuscitation Council, Australian Resuscitation Council, New Zealand Resuscitation Council, Heart and Stroke Foundation of Canada, InterAmerican Heart Foundation, Resuscitation Councils of Southern Africa). Circulation. 2004;110(21):3385-97.

11. Safar P. Resuscitation after brain ischemia. In: Grenvik A, Safar P, editors. Brain failure and resuscitation. New York: Churchill Livingstone; 1981.

12. Herdman M, Gudex C, Lloyd A, Janssen M, Kind P, Parkin D, Bonsel G, Badia $X$. Development and preliminary testing of the new five-level version of EQ5D (EQ-5D-5L). Qual Life Res. 2011;20(10):1727-36.

13. Stiell IG, Nesbitt LP, Nichol G, Maloney J, Dreyer J, Beaudoin T, Blackburn J, Wells GA. OPALS study group. Comparison of the cerebral performance category score and the health utilities Index for survivors of cardiac arrest. Ann Emerg Med. 2009:53(2):241-8.

14. Szende A, Janssen B. Population norms for the EQ-5D. In: Szende A, Janssen B, Cabasés JM, editors. Self-reported population health: an international perspective based on EQ-5D. Springer Open; 2014. p. 21, 25.

15. Björnberg A. Euro Health Consumer Index 2016 Report: Health Consumer Powerhouse; 2017. 100 p.

16. Stichting EuroQol Research Foundation ("EuroQol"). Comparing EQ-5D-3L and EQ-5D-5L value sets. https://euroqol.org/eq-5d-instruments/3l-vs-5l/ comparing-eq-5d-3l-and-eq-5d-5l-value-sets. Accessed 10 June 2019.

17. Graf J, Mülhoff C, Doig GS, Reinartz S, Bode K, Dujardin R, Koch KC, Roeb E, Janssens U. Health care costs, long-term survival, and quality of life following intensive care unit admission after cardiac arrest. Crit Care. 2008; 12(4):R92. 
18. Smith $K$, Andrew E, Lijovic M, Nehme Z, Bernard S. Quality of life and functional outcomes 12 months after out-of-hospital cardiac arrest. Circulation. 2015;131(2):174-81.

19. Perkins GD, Ji C, Deakin CD, Quinn T, Nolan JP, Scomparin C, Regan S, Long J, Slowther A, Pocock H, et al. A randomized trial of epinephrine in out-ofhospital cardiac arrest. N Engl J Med. 2018;379(8):711-21.

20. Ewy GA, Sanders AB. Alternative approach to improving survival of patients with out-of-hospital primary cardiac arrest. J Am Coll Cardiol. 2013;61(2): 113-8.

21. Fukuda T, Yasunaga $H$, Horiguchi $H$, Ohe K, Fushimi K, Matsubara T, Yahagi $\mathrm{N}$. Health care costs related to out-of-hospital cardiopulmonary arrest in Japan. Resuscitation. 2013;84(7):964-9.

22. van Alem AP, Dijkgraaf MG, Tijssen JG, Koster RW. Health system costs of out-of-hospital cardiac arrest in relation to time to shock. Circulation. 2004; 110(14):1967-73

23. Efendijev I, Folger D, Raj R, Reinikainen M, Pekkarinen PT, Litonius E, Skrifvars MB. Outcomes and healthcare-associated costs one year after intensive care-treated cardiac arrest. Resuscitation. 2018;131:128-34

24. Petrie J, Easton S, Naik V, Lockie C, Brett SJ, Stüpfle R. Hospital costs of outof-hospital cardiac arrest patients treated in intensive care; a single Centre evaluation using the national tariff-based system. BMJ Open. 2015;5(4): e005797.

25. Swor R, Lucia V, McQueen K, Compton S. Hospital costs and revenue are similar for resuscitated out-of-hospital cardiac arrest and ST-segment acute myocardial infarction patients. Acad Emerg Med. 2010;17(6):612-6.

\section{Publisher's Note}

Springer Nature remains neutral with regard to jurisdictional claims in published maps and institutional affiliations.

Ready to submit your research? Choose BMC and benefit from:

- fast, convenient online submission

- thorough peer review by experienced researchers in your field

- rapid publication on acceptance

- support for research data, including large and complex data types

- gold Open Access which fosters wider collaboration and increased citations

- maximum visibility for your research: over $100 \mathrm{M}$ website views per year

At $\mathrm{BMC}$, research is always in progress.

Learn more biomedcentral.com/submissions 